\title{
PROBIOTIC CHARACTERIZATION OF BACILLUS SUBTILIS STRAIN ISOLATED FROM INFANT FECAL MATTER REVEALED BY 16S rRNA GENE AND PHYLOGENETIC ANALYSIS
}

\author{
DEVARANJAN DAS ${ }^{1}$, CHANDI CHARAN RATH ${ }^{2}$, NAKULANANDA MOHANTY ${ }^{1}$, SMITA HASINI PANDA ${ }^{1 *}$ \\ ${ }^{1}$ Department of Zoology, Maharaja Sri Ram Chandra Bhanja Deo University, Baripada, Odisha, India. ${ }^{2}$ Department of Life Sciences, Rama \\ Devi Women's University, Bhubaneswar, Odisha, India. Email: panda.smita@gmail.com
}

Received: 20 September 2021, Revised and Accepted: 03 November 2021

\section{ABSTRACT}

Objective: The rationale of our study was to isolate and identify the putative probiotic strain from infant fecal matter exhibiting a broad range of antimicrobial activity and to analyze the effect of different culturing conditions on its probiotic properties and the production of antimicrobial metabolites.

Methods: In the present study, bacterial strains were screened for probiotic properties and antimicrobial activity from infant fecal matter ( 6 months-2 years). The effect of varying culture conditions such as tolerance to acid, bile salt, phenol, $\mathrm{NaCl}$, $\mathrm{pH}$, incubation period, and temperature along with autoaggregation assay, hydrophobicity, and hemolysis was studied. The characterization of the potent strain was studied by morphological, biochemical, and 16S rRNA gene sequencing along the phylogenetic affiliation of the strain was studied.

Results: Two putative probiotic bacteria (DAM and IFM) were isolated, identified, characterized, and predicted at pH 2.0, 3.0, and 4.0, the isolate IFM had $50 \%, 60 \%$, and $70 \%$ survivability, while isolate DAM had $55 \%, 63 \%$, and $75 \%$ survivability, respectively. At a bile salt concentration of $0.5 \%$, both isolates had a $75 \%$ survival rate. The isolates exhibited a high percentage of hydrophobicity and autoaggregation. The isolates also had nonhemolytic activity and were susceptible to many clinical tested antibiotics (tetracycline, erythromycin, ampicillin, gentamycin, penicillin, etc.). The isolate showed antimicrobial activity against enteric pathogens such as Staphylococcus aureus, Escherichia coli, and Shigella dysenteriae. The accession number of Bacillus subtilis MT279753 and MK453362 was submitted to NCBI.

Conclusion: The result revealed that isolates have potent probiotic properties and possess a direct influence on the production of antimicrobial metabolites. These parameters can be modified for the improvement of the potentiality of the isolates.

Keywords: Probiotics, Antimicrobial activity, Phylogenetic analysis, Bacillus spp., 16s rRNA Secondary structure.

(C) 2021 The Authors. Published by Innovare Academic Sciences Pvt Ltd. This is an open access article under the CC BY license (http://creativecommons.org/ licenses/by/4.0/) DOI: http://dx.doi.org/10.22159/ajpcr.2021v14i12.43204. Journal homepage: https://innovareacademics.in/journals/index.php/ajpcr

\section{INTRODUCTION}

Probiotics are considered to be live microbial feed supplements. It is known to exert beneficial effects on the host by improving its intestinal microbial balance $[1,2]$. Most of the commercially available probiotic strains are Lactobacillus sp. and Bifidobacterium sp [3,4]. However, Bacillus sp. have been considered as potential probiotic strains in various dietary supplements [5,6]. The advantage of Bacillus sp. over other probiotic strains is they can survive in foods that require harsh processing conditions such as high temperature and pressure [7]. Bacillus sp. which are commonly used in different feed supplements as probiotics are Bacillus coagulans, Bacillus subtilis, Bacillus licheniformics, Bacillus cereus, Bacillusnatto (subtilis), Bacillus clause, Bacillus pumilus, Bacillus amyloliquefaciens, and Bacillus polyfermenticus [8,7]. Bacillus sp. are considered to be a highly potential probiotic due to its beneficial effects i.e. secretion of antimicrobials, stimulation of immune system, resistance to high acid, bile salt, non-hemolytic activity, and improvement of the gut microbiome $[4,8]$

In general, $B$. subtilis as a probiotics strain has shown outstanding health-boosting records [9-12]. Their application with certain immunedeficient populations especially for critically ill, neonates, and elderly groups should be evaluated and regulated carefully since reports related to bacteria in an immune-compromised patient treated with spore former and other probiotics have been recorded, repetitively [13]. Food additives and therapeutic supplements are lately seeing extensive use of probiotics, especially as digestion enhancers. Ubiquitously found endospore-forming Gram-positive bacterium of the Bacillus group produces several vitamins and digestive enzymes and $B$. subtilis are used as probiotics.

In the present study, we undertook the task of screening and examining potential probiotic bacteria, particularly those with antimicrobial and bacteriocin-producing properties from the feces of healthy newborn babies collected from Mayurbhanj District Hospital. The probiotic products being marketed as functional food, dietary supplements, or drug are also elucidated by the state of probiotic strains. The quality of commercial probiotic products is an important issue to be considered for regulation. In our research, the findings proved the probiotic potency of known probiotic $B$. subtilis is used as the clear implication for future research in the field and to develop our isolates as probiotics for human and animal nutrition. Studies and screening of lactic acid bacteria (LAB) from fermented vegetables, steamed buns, yogurt, and other materials have previously been pursued by many researchers but a few attempts is initiated to screen antibacterial LAB from the feces of newborn infants.

\section{METHODS}

\section{Isolation}

Samples were collected from infant fecal matter (6 months-2 year old), from Mayurbhanj district hospital, Mayurbhanj, Odisha, India. They were diluted by serial dilution method and plated using MRS agar media by spread plate and pour plate method. Plates were then incubated at $37^{\circ} \mathrm{C}$ for $48 \mathrm{~h}$. Colonies were randomly selected based on morphological differences. The isolates were maintained on MRS agar slants at $30^{\circ} \mathrm{C}$ and preserved as frozen glycerol stocks. From the stock, propagation of isolates was done to MRS broth medium which was considered as working culture. 


\section{Identification of source organism}

One gram of fecal matter sample was added in $100 \mathrm{~mL}$ distilled water and kept in a rotator shaker for about $30 \mathrm{~min}$. After shaking the sample was serially diluted. $100 \mu \mathrm{L}$ of each from $10^{-4}$ to $10^{-7}$ tubes were taken from the diluted sample and were spread over the MRS agar plates. The samples were incubated at $37^{\circ} \mathrm{C}$ for $12-24 \mathrm{~h}$. The isolates were identified using Bergey's manual of determinative bacteriology approach, which included morphological and biochemical characterization [14]. Further, 16S rRNA sequence analysis of the isolates was performed to ensure that the isolates were correctly identified to species level.

\section{Morphological characterization of isolate}

Bacterial isolates were inoculated on MRS media and incubated for 12$24 \mathrm{~h}$ at $37^{\circ} \mathrm{C}$. The colony morphology was noted with detail to shape, size, color, and texture, and colonies were detected under a high-power magnifying lens.

\section{Screening for probiotic properties}

All the isolates were screened for their probiotic properties. The screening was done for acid tolerance, bile salt tolerance, phenol tolerance, $\mathrm{NaCl}$ tolerance, antibiotic sensitivity, antimicrobial activity, autoaggregation, and hydrophobicity of all the isolation using standard methods [15].

\section{Tolerance to acid}

Acid tolerance of isolates was done following the method of Del Re et.al. [16]. In the process, each isolate was grown overnight in MRS broth medium at $37^{\circ} \mathrm{C}$. The culture was then centrifuged $(8000 \mathrm{rpm}$ for $5 \mathrm{~min}$ ) and the cell pellets were collected. The collected cell pellets were washed twice in sterile phosphate buffer saline (PBS, pH 7.3) and re-suspended in $1 \mathrm{~mL}$ of PBS of different $\mathrm{pH}(1,2,3,4)$ sequentially. Bacteria cells from the condition were transferred to BHI agar plates and incubated at $37^{\circ} \mathrm{C}$. The viable cells in each plate at the time interval of $0,60,120$, and $180 \mathrm{~min}$ were recorded and $\mathrm{CFU} / \mathrm{mL}$ was calculated. Based on the values, survival percentage of strains was calculated.

\section{Tolerance to bile salt}

Bile salt tolerance was tested according to the method given by Patel et al. [17]. $100 \mu \mathrm{L}$ of overnight grown isolate culture were inoculated into $900 \mu \mathrm{L}$ MRS broth which was pre supplemented with $0.3,0.5$, $1.0,1.5,2.0,2.5,3,3.5$, and $4 \%$ of bile salt. The inoculation was then incubated for $24 \mathrm{~h}$ at $37^{\circ} \mathrm{C}$. From each bile salt concentration medium, $100 \mu \mathrm{L}$ of culture was plated into MRS agar plate medium and incubated again for $24 \mathrm{~h}$ at similar conditions. The growth of bacterial strains was presented in $\log _{10} \mathrm{CFU} / \mathrm{mL}$ and the percentage of survival of bacteria was determined.

\section{Tolerance to phenol}

To estimate the phenol tolerance, $100 \mu \mathrm{L}$ of isolate culture grown overnight were inoculated into $900 \mu \mathrm{L}$ MRS broth medium supplemented with $0.1-0.5 \%$ of phenol and were incubated for $24 \mathrm{~h}$ at $37^{\circ} \mathrm{C}$ [18]. After incubation, the absorbance of each medium at $600 \mathrm{~nm}$ was measured taking MRS broth medium without phenol as a reference and the survival percentage of each strain was determined.

\section{Tolerance to $\mathrm{NaCl}$}

To estimate the $\mathrm{NaCl}$ tolerance, $100 \mu \mathrm{L}$ of isolate culture grown overnight were inoculated into $900 \mu \mathrm{L}$ MRS broth medium supplemented with 2, $4,6,8,10$, and $12 \%$ of $\mathrm{NaCl}$ and were incubated $24 \mathrm{~h}$ at $37^{\circ} \mathrm{C}$ [19]. After incubation, the absorbance of each medium at $600 \mathrm{~nm}$ was measured taking MRS broth medium without $\mathrm{NaCl}$ as a reference and the survival percentage of each strain was determined.

\section{Antibiotic susceptibility test}

The antibiotic susceptibility test of isolates was done against some regular antibiotics, including levofloxacin $(5 \mathrm{mg})$, gentamycin (10 mg), tetracycline (10 mg), ampicillin (10 mg), norfloxacin (10 mg), erythromycin (15 mg), chloramphenicol (30 mg), and cefoperazone (75 mg). The isolates were spread on the lawn of MRS agar plates and were incubated overnight at $37^{\circ} \mathrm{C}$ for $24 \mathrm{~h}$. The antibiotics were then placed at each plate aseptically and incubated. After incubation, a zone of inhibition was observed [20].

\section{Determination of antimicrobial activity}

For the antimicrobial test, the test pathogens were collected from MTCC, IMTECH, Chandigarh, India. The pathogens were Staphylococcus aureus, Shigella dynsentriea, Candida albicans, Escherichia coli, and Listeria monocytes. The antimicrobial activity of isolates was done by a good diffusion method where the overnight culture of pathogens was inoculated in a nutrient agar medium and the isolates were incubated in an MRS broth medium for $24 \mathrm{~h}$ at $37^{\circ} \mathrm{C}$. After incubation, the pathogens were overlaid on the test bacterial spot. The zone of inhibition was observed and the antimicrobial activity of each isolate against each test pathogen was evaluated [18].

\section{Auto aggregation assay}

Auto aggregation assay was performed according to Del Re et.al. [16]. In the assay, each isolate was grown overnight in an NA broth medium at $37^{\circ} \mathrm{C}$. The culture was then centrifuged ( $8000 \mathrm{rpm}$ for $5 \mathrm{~min}$ ) and the cell pellets were collected. The collected cell pellets were washed twice in sterile (PBS, pH 7.3) and re-suspended in $1 \mathrm{ml}$ of PBS to get an OD of 0.5 at $\mathrm{A}_{600}$ and considered as $\mathrm{A}_{0}$. After that, $4 \mathrm{ml}$ culture was mixed by gentle vortexing for $10 \mathrm{~s}$ and incubated for $1 \mathrm{~h}$ at $37^{\circ} \mathrm{C}$. After incubation absorbance of the upper suspension was measured as $\mathrm{A}_{\mathrm{t}}$. Auto aggregation \% was expressed as:

$A_{0}-\left(A_{t} / A_{0}\right) \times 100$

(Where at represents the absorbance at time $t=1 \mathrm{~h}$ and $\mathrm{A}_{0}$ the absorbance at $\mathrm{t}=0 \mathrm{~h}$.)

\section{Hydrophobicity of strains}

According to Rosenberg et al [21], hydrophobicity of strain was measured. In this method, each isolate was grown overnight at $37^{\circ} \mathrm{C}$. The cells were pelleted at $8000 \mathrm{rpm}$ for $5 \mathrm{~min}$ and washed twice with PBS $\mathrm{pH} 7.3$, re-suspended in $0.1 \mathrm{~mol} / \mathrm{L} \mathrm{KNO3} \mathrm{(pH} \mathrm{6.2).} \mathrm{Absorbance} \mathrm{at} \mathrm{A}_{600}$ was measured as $\mathrm{A}_{0}$ using a spectrophotometer (ultraviolet [UV]-visible 1601 Spectrochem, Mumbai). One milliliter of solvent (xylene, acetone, and heptane) was added to $3 \mathrm{~mL}$ of cell suspension. After $10 \mathrm{~min}$ preincubation at room temperature, two phases were mixed by gentle vortexing for $2 \mathrm{~min}$ and incubated at room temperature for $20 \mathrm{~min}$.

\section{Hemolysis of red blood cells}

Each bacterial isolate was streaked on NA agar supplemented with 5\% sheep blood and incubated at $37^{\circ} \mathrm{C}$ for $24 \mathrm{~h}$. The presence of a clear zone around colonies indicated the lysis ability of those colonies and was considered as a positive result.

\section{Secondary screening by specific assay methods Bacitracin like} Inhibition Studies (BLIS)

BLIS was adapted for characterizing the antibiotic-producing strains against human test pathogens. This specific assay was also known as secondary screening [22]. The isolate was cultured in a broth and incubated at $37^{\circ} \mathrm{C}$, for $24 \mathrm{~h}$. The test isolate was lawn cultured ( $1 \mathrm{inch}$ ) at the center of the MHA plate with the help of a sterile cotton swab and incubated at $37^{\circ} \mathrm{C}$, for $24 \mathrm{~h}$. After the incubation period, the bacterial mass was swept out from the plate aseptically with the help of a sterile slide then the plate was exposed to chloroform vapor for $40 \mathrm{~min}$ followed by exposure to UV radiation for $1 \mathrm{~h}$, to ensure the death of the cells. Then freshly grown cultures of the test pathogens were streaked across the plates and incubated at $37^{\circ} \mathrm{C}[23]$.

\section{Analysis of isolates}

Strains were analyzed from infant fecal matter using the 16S rRNA gene and phylogenetic approach $[24,25]$. The 16 S rRNA gene makes it the "Ultimate molecular chronometer" [26] and the most common genetic marker. The 16S rRNA genes are a useful target for phylogeny and clinical identification. This study was done through amplification of the 16SrRNA gene using a set of primer (27F 5'-AGAGTTTGATCTGGCTCAG -3'1492R 
5'-CGGTTACCTTGTTACGACTT-3'). The gene is used for phylogenetic studies due to its highly conserved region among bacterial species. For this reason, $16 \mathrm{~S}$ rRNA is considered as the reliable molecular clock that lineages distantly related bacteria which have similar functionality. The 16S rRNA gene sequences are very often used in the identification, classification, and quantification of microbes $[27,28]$. The DNA sequence was analyzed using an online (nucleotide Basic Local Alignment Search Tool) (n BLAST) [29]. The phylogenetic tree was prepared by neighborjoining using pair-wise alignment in MEGA 7 software.

\section{Modeling of RNA secondary strain}

For the modeling of $16 \mathrm{~S}$ rRNA secondary structure, M fold software is used. This algorithm widely uses the minimal free energy state. $\mathrm{M}$ fold calculates energy metrics that determine all optimal and suboptimal secondary structures for RNA molecules. Plot fold displays the optimal and suboptimal secondary structure for an RNA molecule. The stem-loop finds all possible stems and stems can be plotted with the Dot plot.

\section{Statistical analysis}

There were three replicates of experiments conducted for the independent characterization of two isolates. Hence, the mean values of data were taken for statistical analysis. Pearson-correlation analysis was performed to find out the linear association among the variables. All the analysis was carried out using SPSS statistical software, version 20.

\section{RESULTS AND DISCUSSION}

Strain isolation and identification

According to the method of Bergey's manual of determinative bacteriology, the two selected isolates (DAM and IFM) were identified as B. subtilis. Allowing to the morphological features the two isolated strains appeared yellowish roughed surfaces with irregular margins. Microscopically, the isolates appeared as Gram positive. The bacterial strains grow at $\mathrm{pH} 5.5-8.5$ and temperature at $25-30^{\circ} \mathrm{C}$.

Phylogenetic analysis was done using 16S rRNA gene analysis of isolates with expected base pairs of DAM and IFM, respectively [29]. After performing a BLAST search isolates DAM and IFM exhibited close association with known B. subtilis with a GC content of 53\% and 55\%, respectively. The sequences were aligned by cluster alignment method and a phylogenetic tree was generated using MEGA software. The phylogenetic relationship among different isolates of $B$. subtilis based on nucleotide region of ribosomal 16S rRNA sequence was showing rooted "neighbor-joining" tree. In the phylogenetic tree, DAM and IFM were assigned to the $B$. subtilis group, while the rest of the accessions were assigned to the other group. The phylogenetic tree reveals that the B. subtilis isolated from infant fecal matter has a great diversity. The GC

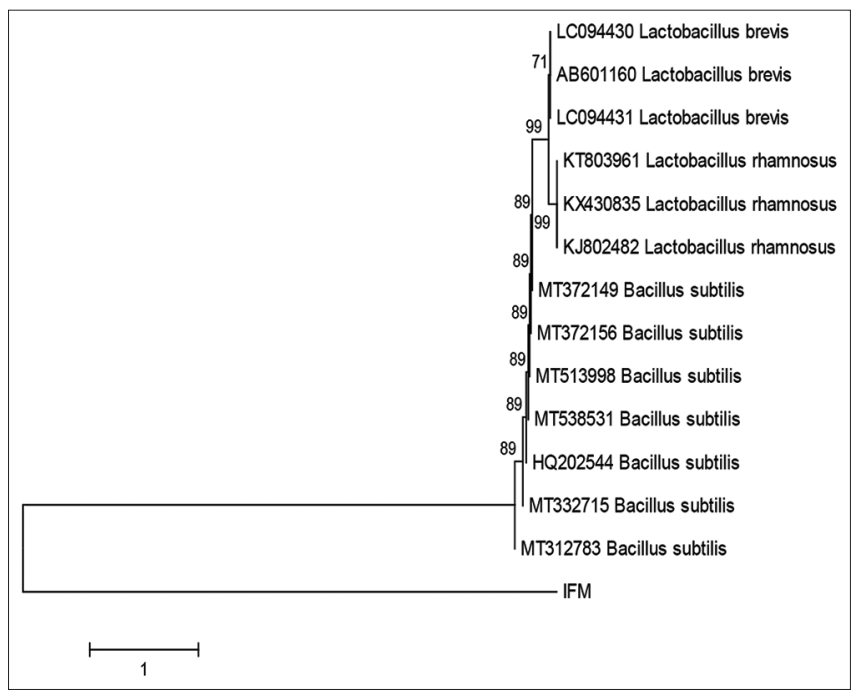

Fig. 1: Evolutionary taxa (phylogenetic tree by NJ Method) content percentage for the two isolated strains was calculated and the GC content found more than 52\% (Figs. 1 and 2).

At the center and interspecies levels, the bacteria 16S rRNA sequences are good indicates of phylogenetic relationship. At the genus level, the study of 16S rRNA gene sequence analysis provided the best identification of the isolates. Partial sequencing of the $16 \mathrm{~S}$ rRNA gene is considered a good alternative for phenotypic identifications and placing isolates in their appropriate taxonomic position. It is confirmed that the two samples from different sources belong to $B$. subtilis isolates. The 16s amplified products of isolate with 100bp ladder shown in Fig. 3.

\section{Probiotic properties}

Acid tolerance

The in vitro screening for resistance to the acidity of the stomach is one of the characteristics to learn about the probiotic effects of strains in the gut. Therefore, while studying the growth and viability of the isolates at different $\mathrm{pH}$, it was observed that the isolate IFM could show survivability (60-70\% viability) at $\mathrm{pH} 2$ and about $80 \%$ survivability at $\mathrm{pH}$ 3. Similarly, the isolate DAM also demonstrated $80 \%$ viability, at $\mathrm{pH}$ indicating that it had probiotic characteristics. Due to the high acidic nature of the gastrointestinal tract, the bacterial spores must

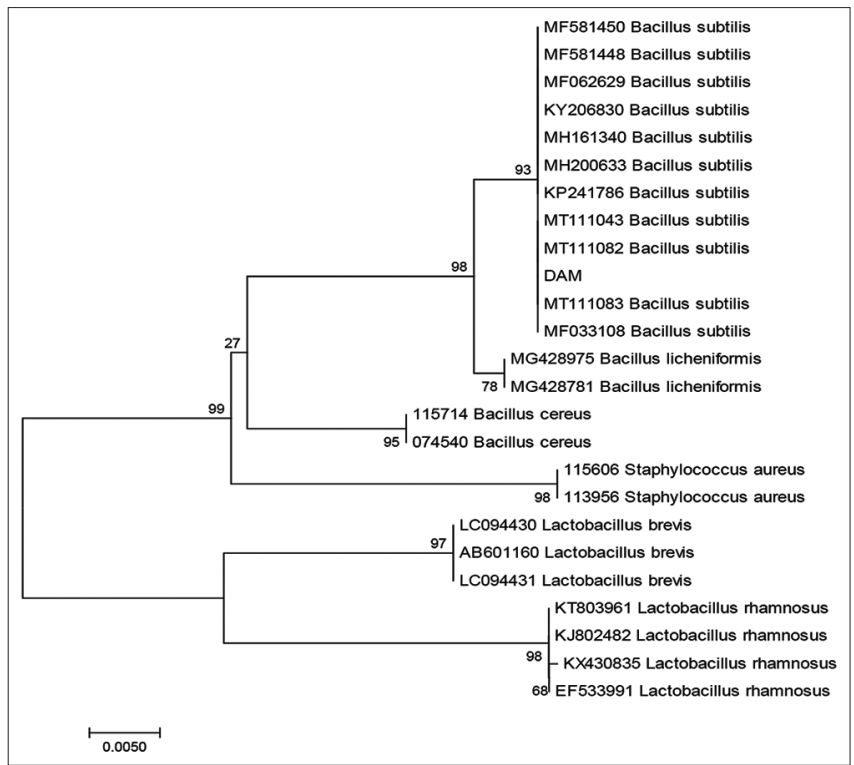

Fig. 2: Evolutionary taxa (phylogenetic tree by NJ Method)

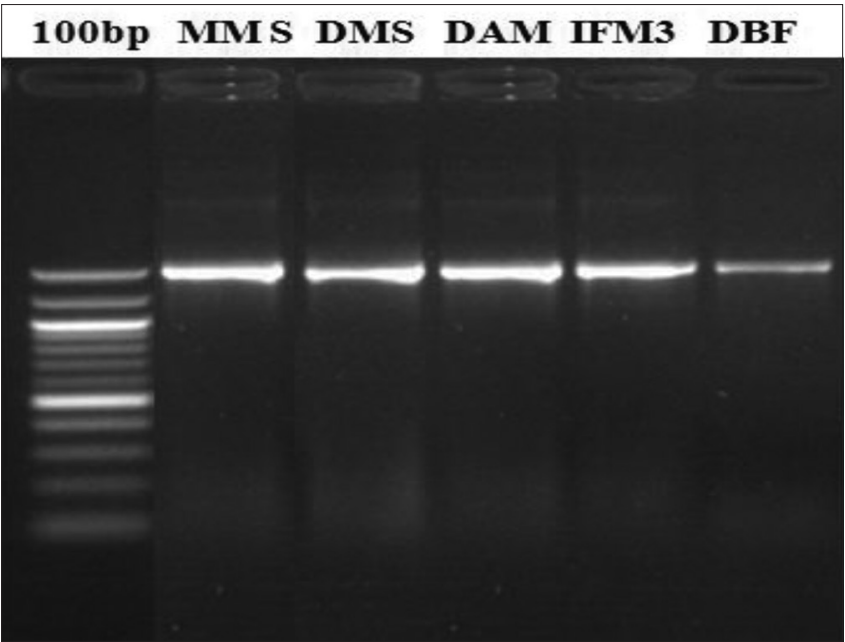

Fig. 3: 16S Amplified products of isolates with 100bp ladder (DAM \& IFM) 
survive and transit to the intestine to exert their properties $[18,30]$. Consequently, it is needed for the bacteria to have protection systems and to counter the low $\mathrm{pH}$ in the stomach. In this study, the selections of potentially probiotic B. subtilis strains were examined for their capability to withstand low $\mathrm{pH}$. According to the activity of the human GI tract varies from 1.5 to 4.5 ; however, the in vitro studies are mostly performed at pH 3 because the viability below is very low. A similar study was reported by Kumar et al., (2009) [31] that E. coli showed higher acid tolerance at $\mathrm{pH} 3$ in comparison to $\mathrm{pH}$ 2. Gangadharan et al. (2010) [18] also reported that viability of Lactococcus at pH 3 was $80 \%$ and $60 \%$ viability at $\mathrm{pH} 2$ which was the same as our study (Fig. 4).

\section{Bile salt tolerance}

Bile salt tolerance is one of the important characteristics of probiotic organisms as they need to survive bile salts in the duodenum to exert their beneficial effects in the gut [31]. The tolerance of the two isolates to bile salts $(0-4 \%)$ was investigated, and it was observed that in the bile salt range of $0.3-2 \%$, the two isolates had a consistent survival rate of $50-80 \%$, and the viability declined as the bile salt concentration increased (Fig. 5). In Bacillus strains, the variability to bile salts is important in estimating bile resistance and selecting viable probiotics. For their positive effects in the gut, probiotic strains must be able to withstand bile salts and allow them to survive and colonize the gastrointestinal tract through enterocyte adhesion [17].

Erkkila and Petaja (2000) [32] reported a similar case study where it showed that strains Pediococcus, acidilactici (P2). Lb. curvatus (RM 10) and Lb. sakei (L2) was resistant to $3 \mathrm{~g} / \mathrm{L}$ bile salt at $\mathrm{pH}$. Bhakta et al. [33] reported that LAB showed the highest tolerance to bile salt at $4 \mathrm{~g} / \mathrm{L}$ concentration.

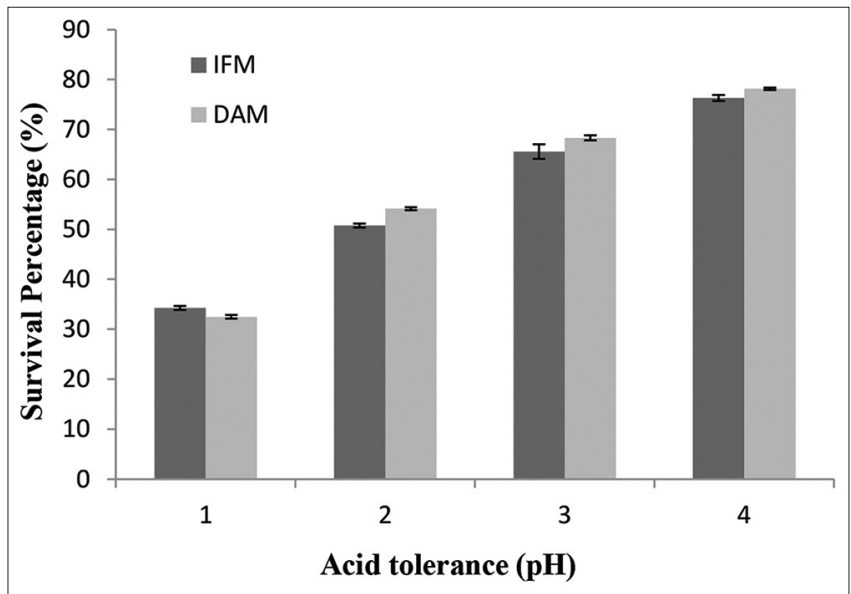

Fig. 4: Acid tolerance of the strain against different $\mathrm{pH}$

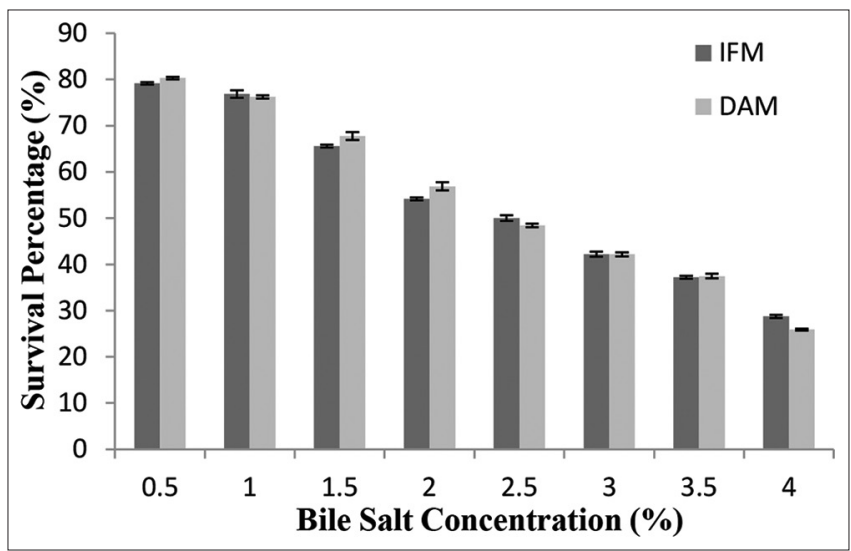

Fig. 5: Survival \% of strain against bile salt concentration

\section{Phenol tolerance}

Tolerance to phenol is beneficial to probiotic bacteria as the aromatic amino acids are derived from dietary-produced proteins and can be delaminated in the gut [34]. For probiotic strain, it was proved that the phenolic compounds can be used in the bacteriostatic effect testing for the resistance and survival in gastrointestinal conditions [35]. Gangadharan et al. [18] reported a relatively high survivability rate ( $70-80 \%$ at $0.2 \%$ phenols, which was reduced to $50 \%$ at $0.4 \%$ phenol and $10 \%$ at $0.6 \%$ phenol, respectively). In our investigation, the results of phenol tolerance of the two isolates' showed a relatively high survival rate $(70-80 \%)$ at $0.2 \%$ phenol and $60 \%$ survival at $0.4 \%$ phenol (Fig. 6).

\section{$\mathrm{NaCl}$ tolerance}

In our study, B. subtilis showed $70-90 \%$ viability at $2 \%(\mathrm{w} / \mathrm{v})$ and $4 \%$ $(\mathrm{w} / \mathrm{v})$ salt concentrations and the percentage of viability reduced to $20 \%$ at $8 \%(\mathrm{w} / \mathrm{v})$ of salt concentration (Fig. 7). As the concentration of $\mathrm{NaCl}$ increased, the viability of the cells began to decline. The growth was completely inhibited/stopped at $12 \% \mathrm{NaCl}$. Our study was highly similar to the study reported by Panda et al. (2014) [36] in which Lactobacillus showed $59-99 \%$ viability at $2 \%$ and $4 \%$ salt concentration. The viability decreased to $5 \%$ and $8 \%$ at $12 \% \mathrm{NaCl}$ concentration. At high salt concentrations uncoupling between growth and energy production occurs where some strains cannot remain viable [37]. A decrease in microbial viability at high salt concentration is often osmotic stress and a significant challenge for microorganisms surviving in the fermentation process [37]. In another study by Wang et al, (2016) [38] reported that Lb. Plantarum ATCC 14917 was able to survive and show the highest viability up to $6 \% \mathrm{NaCl}$ concentration.

\section{Antibiotic resistance study}

For selecting the potential and highly effective probiotic strain, antibiotic resistance plays an important role [39]. The strains of

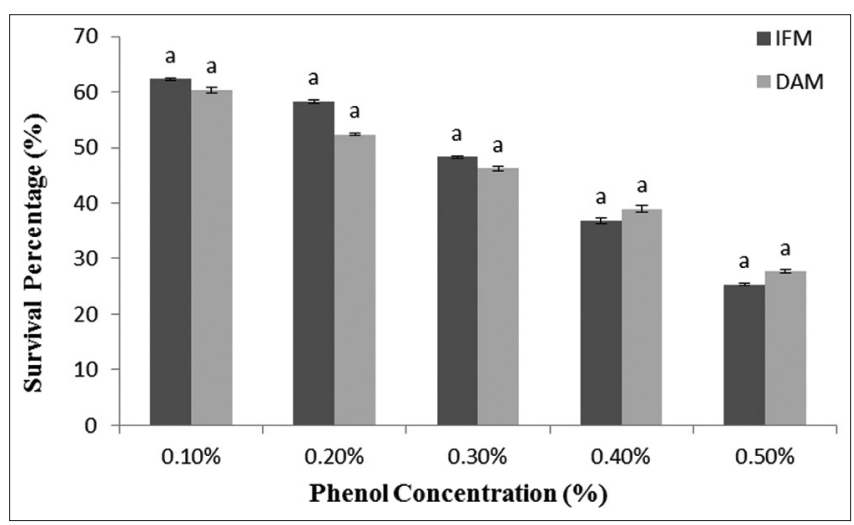

Fig. 6: Survival \% of strain against different phenol concentration

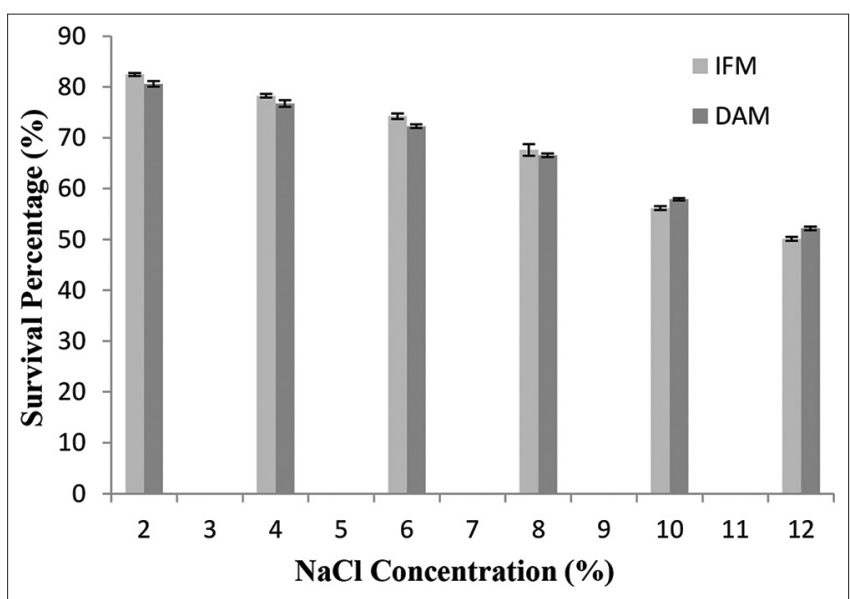

Fig. 7: Survival \% of strain against different $\mathrm{NaCl}$ concentration 


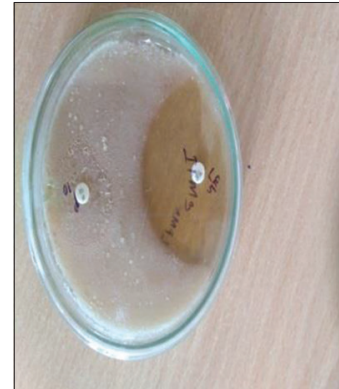

IFM (Levofloxacin)

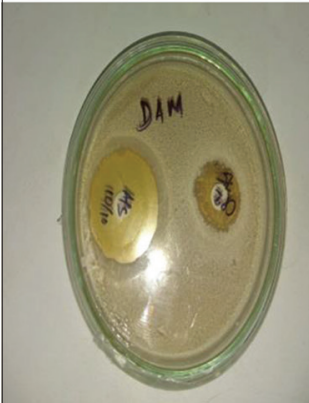

DAM (Levofloxacin)

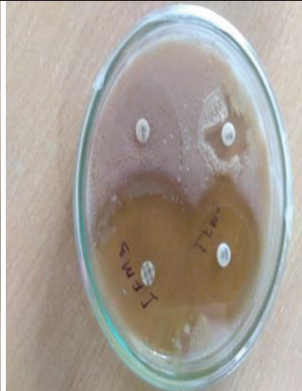

(Chloramphenicol)

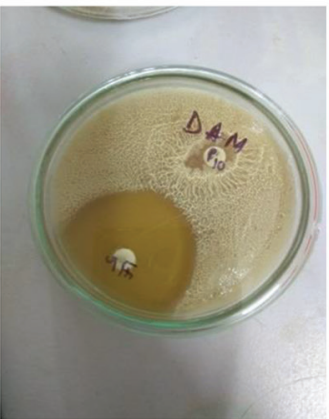

(Chloramphenicol)
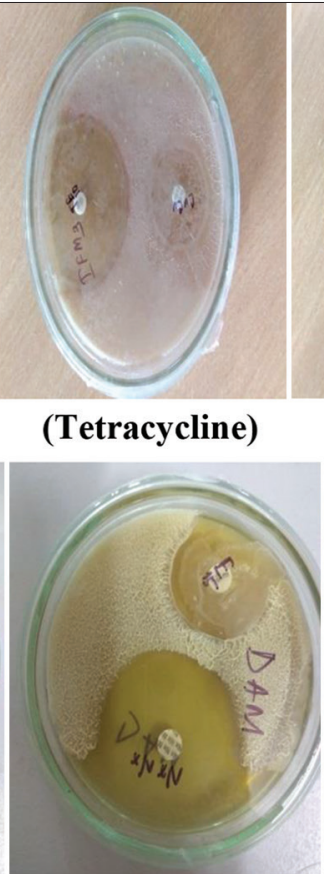

(Tetracycline)
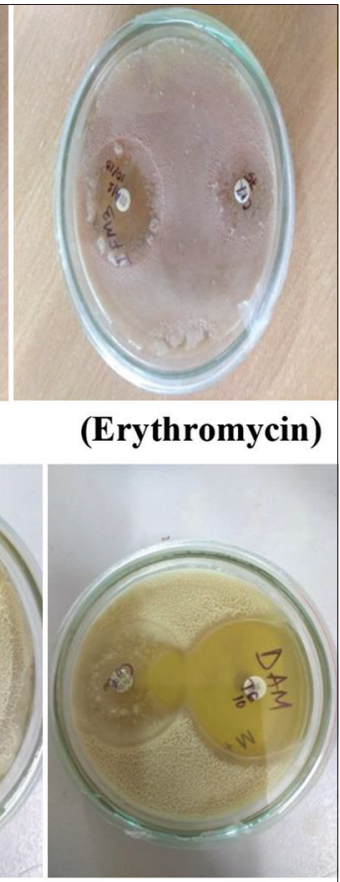

(Erythromycin)

Fig. 8: Antibiotic activity of Bacillus subtilis (IFM and DAM)

B. subtilis (DAM and IFM) were highly susceptible to Levofloxacin, chloramphenicol, and tetracycline and moderately susceptible to all other clinically antibiotic tested (Fig. 8). The antibiotic-resistant properties also indicated that the isolate (B. subtilis) was able to survive in undesirable conditions caused due to the high concentrations of antibiotics. Panda et al. (2017) [40] reported a similar result which was concomitant to our study. They reported that isolate Jc13 was highly susceptible to cefoperazone, tetracycline, and chloramphenicol. Alanber and Khaled (2020) [41] also reported a similar study in which Bacillus Strains were resistant to cefoperagone, ceftazidime, cefepimeetc, and highly sensitive to gentamicin and amikacin. Most of the Bacillus sp. are spore produces and possess the ability to transfer antibiotic resistance genes [42], which carry the property of bacillus for antibiotic resistance.

\section{Antimicrobial activity}

Antimicrobial activity is the most significant property of a viable and functioning probiotic. The antibacterial efficacy of $B$. subtilis strain against several pathogen microorganisms was tested in this study. The isolates showed moderate antimicrobial activity against Klebsiella $\mathrm{sp}$. and E. coli, S. aureus, and Listeria monocytogens. Antimicrobial activity may be a result of organic acids (Fig. 9). The result of antimicrobial activity of two isolates indicates the capacity to inhibit food-borne outbreaks caused by pathogens [18]. The antimicrobial activity possessed by several bacterial strains may be the result of bacteriocins and organic acid production, that is, lactic acid, acetic acid, and formic acid. The effectiveness of antibiotic treatment is however constantly decreasing due to the increasing spread of resistant pathogens [43]. Efremenkova et al. reported a similar study in 2019, where B. subtilis 534 showed a wide range of antimicrobial activities against clinical tested pathogens and fungi [44].

\section{Autoaggregation assay}

Autoaggregation (an important property for probiotics) reflects the adhesion ability to enterocytic cellular lines which provides resistance to peristaltic elimination [42]. Based on sedimentation characteristics of isolates, the autoaggregation was investigated. IFM and DAM showed more than $30 \%$ of autoaggregation ability. Similar work was reported by Patel et al. [17] on Bacillus sp. and showed 32.6\% autoaggregation activity. The colonization of bacteria to intestinal cells is dependent on
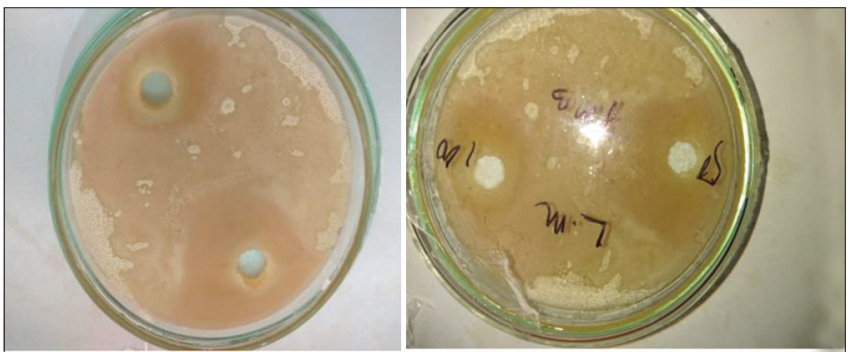

IFM Staphylococcus aureus
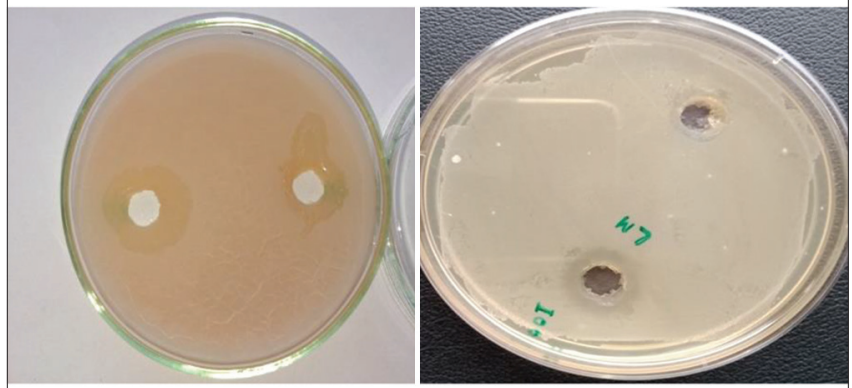

DAM Staphylococcus aureus

Listeria monocytogens

Fig. 9: Antimicrobial activity of Bacillus subtilis (IFM and DAM)

Table 1: Percentage of autoaggregation by DAM and IFM

\begin{tabular}{llll}
\hline Isolates & $\begin{array}{l}\text { Initial OD } \\
\text { at } \mathbf{6 0 0} \mathbf{~ n m}\end{array}$ & $\begin{array}{l}\text { Final OD at } \\
\mathbf{6 0 0} \mathbf{~ n m}\end{array}$ & $\begin{array}{l}\text { Percentage of } \\
\text { auto aggregation }\end{array}$ \\
\hline $\begin{array}{l}\text { DAM } \\
\text { (B. subtilis) }\end{array}$ & 0.378 & 0.274 & $34.68 \%$ \\
$\begin{array}{l}\text { IFM } \\
\text { (B. subtilis) }\end{array}$ & 0.376 & 0.268 & $33.67 \%$ \\
\hline
\end{tabular}

B. subtilis: Bacillus subtilis

the cell surface of hydrophobicity (Table 1). By the probiotics microbes, the colonization of the tissue can prevent pathogens access by steric interactions. 
Hydrophobicity of strains

The IFM isolate showed high hydrophobicity (45.8\%) with acetone whereas the isolate DAM showed $43.7 \%$ hydrophobicity with xylene. High hydrophobicity may be due to the presence of hydrophobic molecules (lipids, cytoplasmic, array, and wall intercalated proteins) on the bacterial surface. Kos et al. [45] reported the $70.96 \%$ and $36.06 \%$ hydrophobicity of Lactobacillus with xylene and chloroform, respectively. In another study, B. subtilis adhered to solvents such as chloroform and hexane with 19 and $11.46 \%$ adhesion, respectively, which was concomitant to the result of Hamadi and Latrache [46] (Table 2).

\section{Hemolytic activity}

The two isolates of B. subtilis were found non-hemolytic ( $\gamma$-hemolysis) on $5 \%$ sheep blood agar. Hemolytic properties contain $\alpha$-hemolysis, $\beta$-hemolysis, and $\gamma$-hemolysis. $\beta$ - Hemolysis is considered harmful and $\alpha$ - and $\gamma$-hemolysis are considered as safe. $\alpha$ - Hemolysis causes the incomplete lysine of erythrocytes, resulting in a green - had zone around the bacterial colonies. $\gamma$ - Hemolysis is without hemolysis. In probiotic strain, the absence of hemolytic nature is considered to be a positive trait for bacteria.

\section{Secondary screening by specific assay methods (BLIS)}

The isolates showed positive antibacterial activity (disc and spot methods) which were subjected to secondary screening. Plates were observed for growth on either side of the lawn and no growth at the center represents the antibacterial activity of the isolate against the test pathogens [22]. It was demonstrated that the two putative probiotic isolates can produce bacteriocins (Fig. 10).

\section{Modeling of RNA secondary strain}

Different strains of $B$. subtilis were studied for secondary structure modeling. The strategy based on free energy proved useful for the identification and thermodynamic characterization of $B$. subtilis strains.

Table 2: Percentage of hydrophobicity of two isolates against different solvent

\begin{tabular}{lllll}
\hline Isolates & Solvents & $\begin{array}{l}\text { Initial OD } \\
\text { at 600 } \mathbf{~ n m}\end{array}$ & $\begin{array}{l}\text { Final OD } \\
\text { at 600 nm }\end{array}$ & $\begin{array}{l}\text { \% of } \\
\text { Hydrophobicity }\end{array}$ \\
\hline DAM & Heptane & 0.292 & 0.192 & $36.55 \%$ \\
(B. subtilis) & Xylene & 0.292 & 0.183 & $33.47 \%$ \\
& Acetone & 0.292 & 0.219 & $45.8 \%$ \\
IFM & Heptane & 0.292 & 0.196 & $37.92 \%$ \\
(B. subtilis) & Xylene & 0.292 & 0.213 & $43.74 \%$ \\
& Acetone & 0.292 & 0.203 & $40.32 \%$ \\
\hline
\end{tabular}

B. subtilis: Bacillus subtilis

Table 3: B. subtilis strains with optimal energy of 16S rRNA secondary structure

\begin{tabular}{ll}
\hline Accession number & Optimal energy Kcl/mol \\
\hline MT279753 IFM (B. subtilis) & $-499.43 \mathrm{Kcl} / \mathrm{mol}$ \\
MK453362 DAM (B. subtilis) & $-488.17 \mathrm{Kcl} / \mathrm{mol}$ \\
\hline
\end{tabular}

B. subtilis: Bacillus subtilis

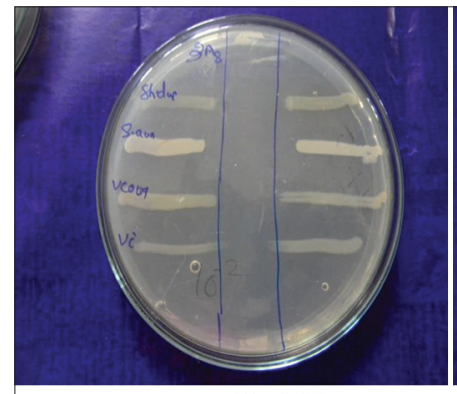

IFM (B.subtilis)

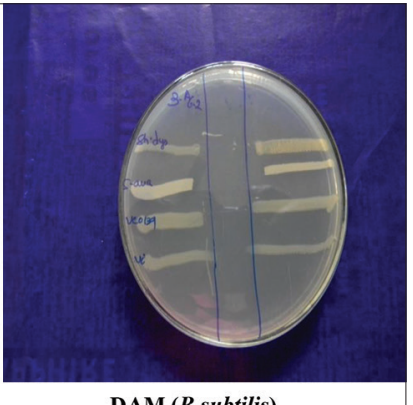

DAM (B.subtilis)
Fig. 10: Bacteriocin like inhibition studies experiment (Secondary screening)
The IFM B. subtilis showed $-499.43 \mathrm{Kcal} / \mathrm{moL}$ of optimal energy while DAM B. subtilis showed $-488.17 \mathrm{Kcal} / \mathrm{moL}$ of optimal energy for 116S rRNA secondary structure (Table 3). The nucleic acid secondary structure dot plot is a triangle plot that represents base pairs as dots. In this dot plot method, the base pairs display in more than one folding at $37^{\circ} \mathrm{C}[47]$

Large well-determined structural domains are identified by visual inspection of an "energy dot plot." These plots show suboptimal output from the RNA folding algorithm. These plots often contain a mixture of clear regions and cluttered regions. Clear regions define well-determined structural domains in the optimal folding. Nucleotides within these regions do not interact with other regions of the molecule in suboptimal folding. Cluttered regions indicate portions of the molecule that have the potential to form numerous alternative structures. Predicted structures in the optimal folding that are located in cluttered regions of the plots are considered to be poorly determined.

It can be used to compare a few folders. Using the efficient algorithm, it is too complicated to multi-branch loops. Therefore, slightly simple rules are used for folding. This simple rule gives the initial free energies and the final energies expressed with the best rules $[48,49]$. This study helped to predict the secondary structure of 16sr RNA and to identify conformational changes (Fig. 11a and 12a). The M fold web server gives suboptimal folding as well as energy dot plots (Fig. 11b and $12 \mathrm{~b}$ ). Energy dot plots are shown the base sets in the anticipated ideal folding (lower left triangle), just as all conceivable base matches on the whole potential foldings inside $12 \mathrm{kcal}$ of the ideal anticipated folding (upper right triangle), and Minimum Free Energy appeared in the figure.

Dynamic writing of certain computer programs is by and large utilized for the optional construction forecast, which likewise helps in the figuring of thermodynamic free energy. To check the proper function of RNA molecule secondary structure, as the optional design is important. We use the $\mathrm{M}$ fold web worker since it utilizes the neighbor energy rules to ascertain the secondary construction of the RNA. M fold ascertains energy networks that decide all ideal and imperfect optional secondary

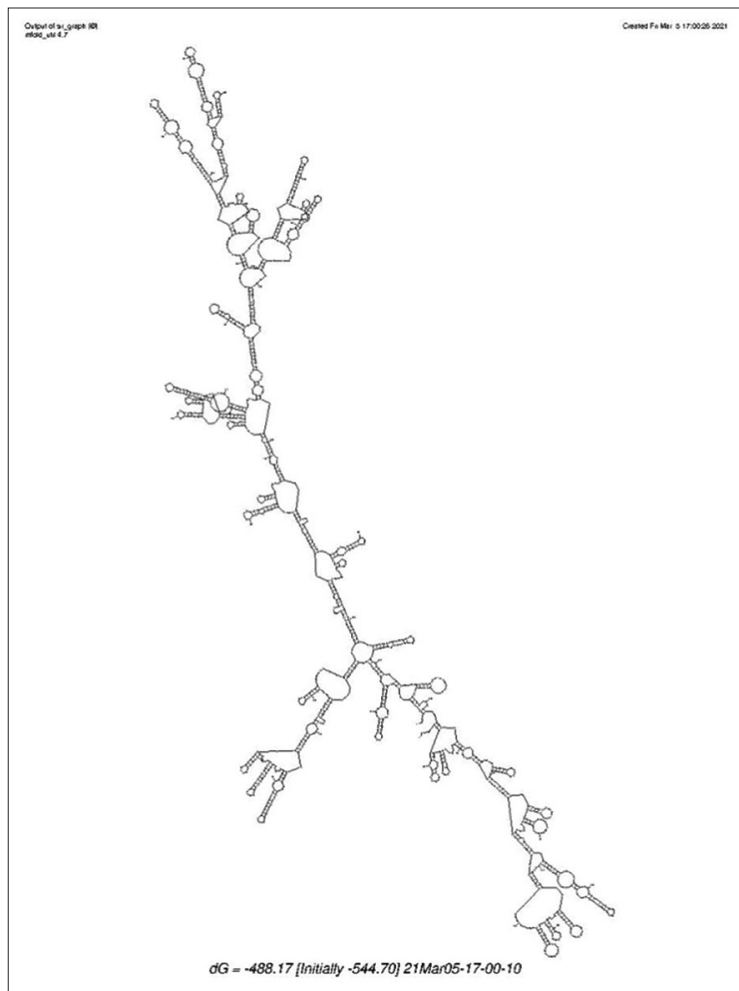

Fig. 11: (a) 16s rRNA of secondary structure, Bacillus subtilis (DAM) 


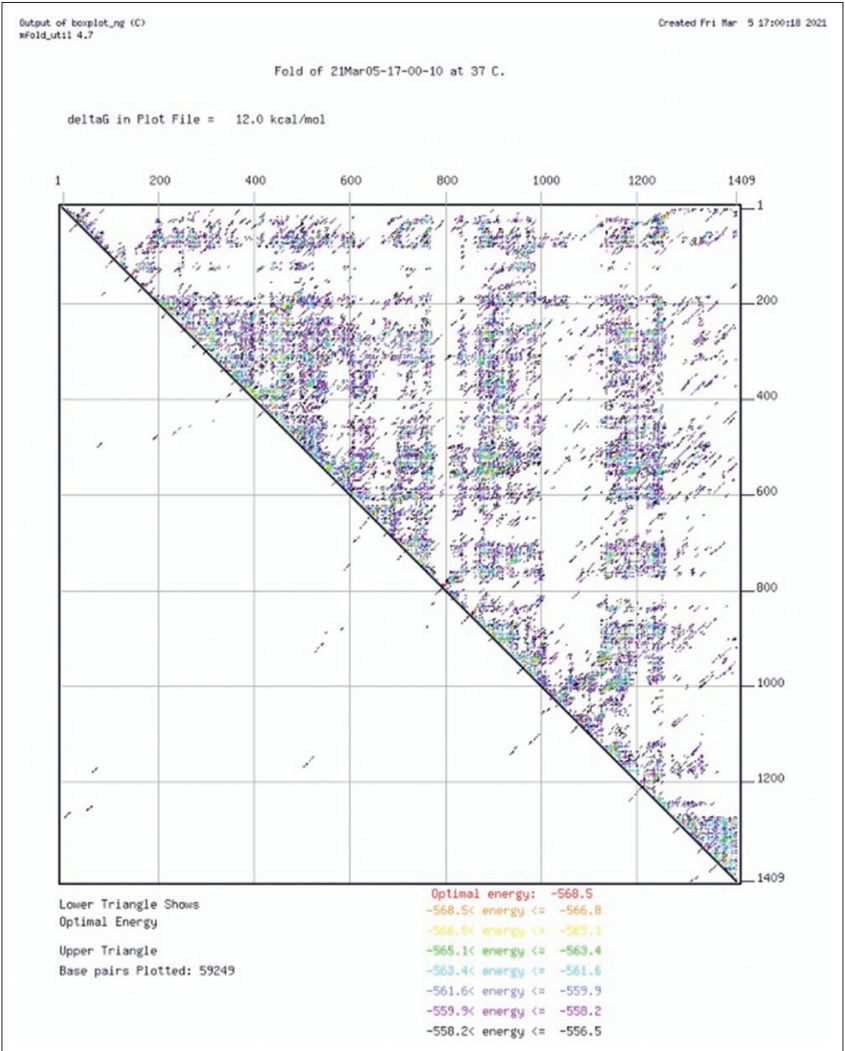

Fig. 11: (b) Energy dot plot for the annotated structure plot of 12-kcal/mol (DAM)

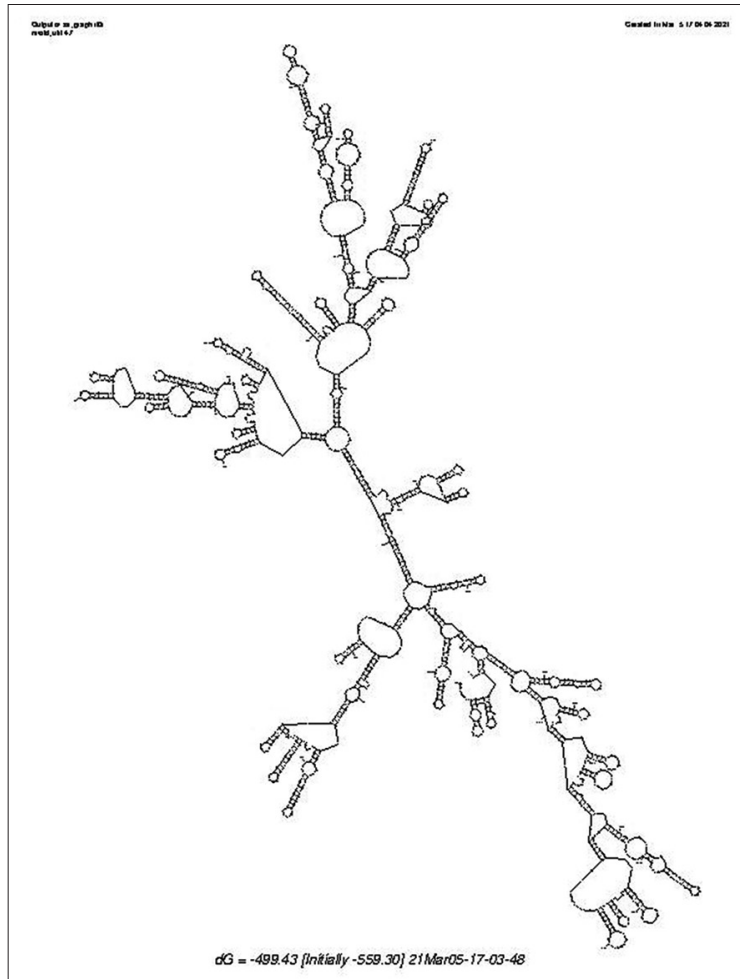

Fig. 12: (a) 16s rRNA of Secondary structure, Bacillus subtilis (IFM)

structures for an RNA molecule. Plot Fold shows the ideal and imperfect optional constructions for an RNA particle anticipated by M fold. Stem

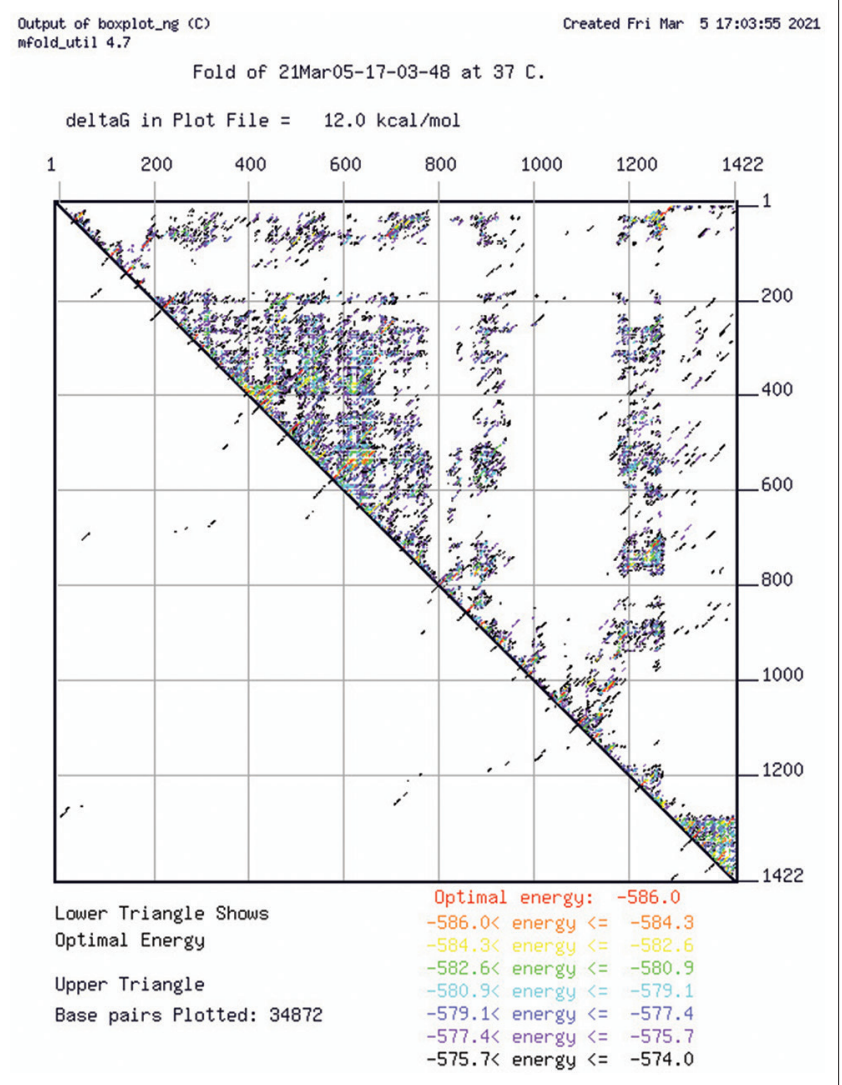

Fig. 12: (b) Energy dot plot for the annotated structure plot of 12-kcal/mol (IFM)

Table 4: Correlation coefficient analysis between bile salt and survivability of two isolates

\begin{tabular}{lll}
\hline Bile salt conc. (\%) & DAM & IFM \\
\hline 1.000 & $-0.823^{* *}$ & $-0.780^{* *}$ \\
& 1.000 & $-0.988^{* *}$ \\
& & 1.000 \\
\hline
\end{tabular}

${ }^{* *}$ Correlation is significant at the 0.01 level (2- tailed)

Loop discovers every single imaginable stem and stems can be plotted with DotPlot. B. subtilis one of the significant microorganisms will create spores because of survivalists under outrageous temperatures. The nucleic acid secondary structure dot plot is triangular a three-sided plot that addresses base sets as dots. The benefits of this speck smudge are that it shows the base sets in more than one folding at $37^{\circ} \mathrm{C}$. It can be used to compare few folders. Utilizing the productive calculation, it is too muddled to even consider creating multi-branch circles.

The outcomes introduced here show that the PC program M fold predicts RNA secondary structures. Diagrammatic portrayal of energy dot plot has appeared in the figure individually for each rRNA. The advancement of computational devices gives the interconnection of grouping and underlying data to comment on and find a secondary design of rRNA.

\section{Statistical analysis}

Pearson's correlation analysis showed that the entire above variable had a significant negative correlation with two isolates (DAM and IFM). When the concentration of bile salt, $\mathrm{NaCl}$ and phenol increased the survivability rate of the isolates decreased. For example, DAM- bile salt tolerance $(-0.823, \mathrm{p}<0.01)$, DAM- Phenol tolerance $(-0.928 \mathrm{p}<0.01)$, IFM- bile salt tolerance $(-0.988, \mathrm{p}<0.01)$, IFM- $\mathrm{NaCl}$ tolerance $(-0.924, \mathrm{p}<0.01)$ (Tables 4-6). 
Table 5: Correlation coefficient analysis between phenol and survivability of two isolates

\begin{tabular}{lll}
\hline Phenol conc. (\%) & DAM & IFM \\
\hline 1.000 & $-0.928^{* *}$ & $-0.856^{* *}$ \\
& 1.000 & $-0.819^{* *}$ \\
& & 1.000 \\
\hline
\end{tabular}

**Correlation is significant at the 0.01 level (two-tailed)

Table 6: Correlation coefficient analysis between $\mathrm{NaCl}$ and survivability of two isolates

\begin{tabular}{lll}
\hline Nacl conc. (\%) & DAM & IFM \\
\hline 1.000 & $-0.960^{* *}$ & $-0.893^{* *}$ \\
& 1.000 & $-0.924^{* *}$ \\
& & 1.000 \\
\hline
\end{tabular}

${ }^{* *}$ Correlation is significant at the 0.01 level (two- tailed)

\section{CONCLUSION}

The two strains of B. subtilis have been proved to be potential probiotic strains due to their survival under higher tolerance to bile salt, $\mathrm{NaCl}$, phenol, and highly acidic conditions. The colonization efficiency was proved by exhibiting high autoaggregation and hydrophobicity. The absence of hemolytic nature made the isolates to be considered potential probiotic strains. Further, the present study helped to predict the secondary structure of $16 \mathrm{~s}$ rRNA and to identify conformational changes with the $\mathrm{M}$ fold web server giving suboptimal folding as well as the "energy dot plot." Depending on energy level which gives different secondary structures and the most stable structure has been selected for the study. All base pairs participated in the folding of the RNA is represents the dot blot and the folding was carried out with the minimum folding energy. And the predicted models are the suited best models.

The study of probiotics as a new concept receiving rapid scientific interest is a recent phenomenon. In the recent scenario, B. subtilis being the potential probiotics is widely used as food bio preservatives. B. subtilis is also produces lipopeptides which show antimicrobial activity [50]. The emergence of probiotics as new science and its application in farming and aquaculture has evolved as an alternative to antibiotics and prophylactics in humans.

\section{CONTRIBUTIONS}

DD isolated the strains, performed morphological, biochemical, probiotic, bioinformatics analysis (phylogenetic and secondary structure prediction), and wrote the manuscript. SHP designed the study, performed statistical analysis of the study. SHP, CCR, and NM supervised the study and revised the manuscript. All authors read and approved the final version of the manuscript.

\section{CONFLICT OF INTERESTS}

The authors declare that they have no conflict of interest regarding the publication of this paper.

\section{FUNDING SOURCES}

Thankful to CSIR, New Delhi, India, for giving him the financial support to carry out this study (File no. 09/1255(0001)/2019).

\section{REFERENCES}

1. Fuller R. Probiotics in man and animals. J Appl Bacteriol 1989;66:365-78

2. Lee GR, Maarouf M, Hendricks AJ, Lee DE, Shi VY. Topical probiotics: The unknowns behind their rising popularity. Dermatol Online J 2019;25:13030.

3. Patel S, Goyal A. The current trends and future perspectives of prebiotics research: A review. 3 Biotech 2012;2:115-25.
4. Lee S, Lee J, Jin YI, Jeong, JC, Chang YH, Lee Y, et al. Probiotic characteristics of Bacillus strains isolated from Korean traditional soy sauce. LWT 2017;79:518-24.

5. Lefevre M, Racedo SM, Ripert G, Housez B, Cazaubiel M, Maudet C, et al. Probiotic strain Bacillus subtilis CU1 stimulates the immune system of elderly during common infectious disease period: A randomized, double-blind placebo-controlled study. Immun Aging 2015;12:1-11.

6. Suva M, Sureja V, Kheni D. Novel insight on probiotic Bacillus subtilis: Mechanism of action and clinical applications. J Curr Res Sci Med 2016;2:65.

7. Mihooliya KN, Nandal J, Swami L, Verma H, Chopra L, Sahoo DK. A new $\mathrm{pH}$ indicator dye-based method for rapid and efficient screening of 1 -asparaginase producing microorganisms. Enzym Microb Technol 2017;107:72-81.

8. Lim H, Oh S, Yu S, Kim M. Isolation and characterization of probiotic Bacillus subtilis MKHJ 1-1 possessing L-asparaginase activity. Appl Sci 2021;11:4466.

9. Khodadad A, Farahmand F, Najafi M, Shoaran M. Probiotics for the treatment of pediatric Helicobacter pylori infection: A randomized double blind clinical trial. Iran J Pediatr 2013;23:79-84.

10. Kacena MA, Merrell GA, Manfredi B, Smith EE, Klaus DM, Todd P. Bacterial growth in space flight: Logistic growth curve parameters for Escherichia coli and Bacillus subtilis. Appl Microbiol Biotechnol 1999;51:229-34.

11. Alkaya B, Laleman I, Keceli S, Ozcelik O, Haytac MC, Teughels W. Clinical effects of probiotics containing Bacillus species on gingivitis: A pilot randomized controlled trial. J Periodontal Res 2016;52:497-504

12. Lopetuso LR, Scaldaferri F, Franceschi F, Gasbarrini A. Bacillus clausii and gut homeostasis: State of the art and future perspectives. Expert Rev Gastroenterol Hepatol 2016;10:943-8.

13. Doron S, Snydman DR. Risk and safety of probiotics. Clin Infect Dis 2015;60:S129-34

14. Holt JG, Krieg RN, Sneath PHA. Bergey's Manual of Determinative Bacteriology. $9^{\text {th }}$ ed. Baltimore, MD: Williams and Wilkins; 1994.

15. Sathyabama S, Vijayabharathi R, Brunthadevi P, Ranjith KM, Priyadarisini VB. Screening for probiotic properties of strains isolated from feces of various human groups. J Microbiol 2012;50:603-12.

16. Del Re B, Sgorbati B, Miglioli M, Palenzona D. Adhesion, autoaggregation and hydrophobicity of 13 strains of Bifidobacterium longum. Lett Appl Microbiol 2000;31:438-44.

17. Patel AK, Ahire JJ, Pawar SP, Chaudhari BL, Shouche YS, Chincholkar SB. Evaluation of probiotic characteristics of siderophoregenic Bacillus spp. Isolated from dairy waste. Appl Biochem Biotechnol 2010;160:140-55.

18. Gangadharan D, Sivaramakrishnan S, Pandey A, Nampoothiri KM. Folate-producing lactic acid bacteria from cow's milk with probiotic characteristics. Int J Dairy Technol 2010;63:339-48.

19. Panda SK, Patra AK, Kar RN. Monitoring of multiple drug-resistance pathogens in a selected stretch of Bay of Bengal, India. Environ Monit Assess 2012;184:193-200

20. Patel SA, Parikh SC. Isolation and sreening of probiotic potential lactic acid bacteria from local dairy products. Int J Curr Microbiol Appl Sci 2016;5:490-8.

21. Rosenberg M, Gutnick D, Rosenberg E. Adherence of bacteria to hydrocarbons: A simple method for measuring cell-surface hydrophobicity: FEMS Microbiol Lett 1980;9:29-33.

22. Udhayashree N, Senbagam D, Senthilkumar B, Nithya K, Gurusamy R. Prodauction of bacteriocin and their application in food products. Asian Pac J Trop Biomed 2012;2:406-10.

23. Tag JR, Mcgiven AA. Assay system for bacteriocins. J Appl Microbiol 1971;21:943

24. Van de Peer Y, Jansen J, De Rijk P, De Wachter R. Database on the structure of small ribosomal subunit RNA. Nucleic Acids Res 1997; $25: 111-6$

25. Maidak BL, Olsen GJ, Larsen N, Overbeek R, McCaughey MJ, Woese CR. Ribosomal database project (RDP). Nucleic Acid Res 1996;24:82-5.

26. Drancourt M, Bollet C, Carlioz A, Martelin R, Gayral JP, Raoult D. $16 \mathrm{~S}$ ribosomal DNA sequence analysis of a large collection of environmental and clinical unidentifiable bacterial isolates. J Clin Microbiol 2000;38:3623-30.

27. Janda JM, Abbott SL. 16S rRNA gene sequencing for bacterial identification in the diagnostic laboratory: Pluses, perils, and pitfalls. J Clin Microbiol 2007;45:2761-4.

28. Kubo Y, Rooney AP, Tsukakoshi Y, Nakagawa R, Hasegawa H, 
Kimura K. Phylogenetic Analysis of Bacillus subtilis strains applicable to natto (fermented soybean) production. Appl Environ Microbiol 2011;77:6463-9.

29. Saitou N, Nei M. The neighbor-joining method: A new method for reconstructing phylogenetic trees. Mol Biol Evol 1987;4:406-25.

30. Ahire JJ, Patil KP. Chaudhari BL, Chincholkar SB. Bacillus spp. of human origin: A potential siderophoregenic probiotic bacteria. Appl Biochem Biotechnol 2011;164:386-400.

31. Kumar P, Ferzin S, Chintan S, Kumar NG. Isolation and characterization of potential probiotic Escherichia coli strains from rat fecal samples. Am J Infect Dis 2009;5:387-93.

32. Erkkila S, Petaja E. Screening of commercial meat starter cultures at low $\mathrm{pH}$ in the presence of bile salts for potential probiotic use. Meat Sci 2000;55:297-300.

33. Bhakta JN, Ohnishi K, Munekage Y, Iwasaki K, Wei MQ. Characterization of lactic acid bacteria-based probiotics as potential heavy metal sorbents. J Appl Microbiol 2012;112:1193-206.

34. Perez-Mirinda S, Cabirol N, Tellez RG, Zamudio-Rivera LS, Fernández FJ. O-CAS, a fast and universal method for siderophoredetection. J Microbiol Methods 2007;70:127-31

35. Gomes BC, de Melo FB, De Martinis EC. Dualistic aspects of Enterococcus spp. in foods. Appl Microbio Biotechnol 2010;:1119-25.

36. Panda SH, Das S, Mohanty N. Fortification of fruit juices by probiotic lactic acid bacteria producing siderophore isolated from infant faecal matter. JAM 2014; 1:286-96.

37. Yao M, Xie J, Du H, McClements DJ, Xiao H, Li L. Progress in microencapsulation of probiotics: A review. Compr Rev Food Sci Food Saf 2020;11:1541-4337.

38. Wang Z, Wang L, Chen Z, Ma X, Yang X, Zhang J, et al. In vitro evaluation of swine-derived Lactobacillus reuteri: Probiotic properties and effects on intestinal porcine epithelial cells challenged with enterotoxigenic Escherichia coli K88. J Microbiol Biotechnol 2016;26:1018-25.

39. Hu Q, Dou M, Qi H, Xie X, Zhuang G, Yang M. Detection, isolation, and identification of cadmium-resistant bacteria based on PCR-DGGE. J Environ Sci 2007;19:1114-9.

40. Panda SK, Behera SK, Qaku XW, Sekar S, Ndinteh DT, Nanjundaswamy HM, et al. Quality enhancement of prickly pears (Opuntia sp.) juice through probiotic fermentation using Lactobacillus fermentum-ATCC 9338. LWT Food Sci Technol 2017;75:453-9.

41. Alanber MN, Alharbi NS, Khaled JM. Evaluation of multidrug-resistant Bacillus strains causing public health risks in powdered infant milk formulas. J Infect Public Health 2020;13:1462-8.

42. Sharpe M, Elizabeth-Pyer TF. Identification of lactic acid bacteria, In: Gibbs BM, Skinner FA, editors. Identification Methods for Microbiologists. New York: Academic Press; 1996. p. 65-79.

43. Savustianenko AV. Mechanisms of action of probiotics based on Bacillus subtilis. Actual Infectol 2016;2:35-44.

44. Efremenkova O, Gabrielyan N, Malanicheva I, Demiankova M, Efimenko T, et al. Antimicrobial properties of the probiotic strain Bacillus subtilis 534. Int Arch Med Microbiol 2019;2:008

45. Kos B, Šušković J, Vuković S, Šimpraga M, Frece J, Matošić S. Adhesion and aggregation ability of probiotic strain Lactobacillus acidophilus M92. J Appl Microbiol 2003;94:981-7.

46. Hamadi F, Latrache H. Comparison of contact angle measurement and microbial adhesion to solvents for assaying electron donor-electron acceptor (acid-base) properties of bacterial surface. Colloid Surface 2008;65:134-9.

47. Xia T, Lucia JS Jr., Burkard ME, Kierzek R, Schroeder SJ, Jiao X, et al. Thermodynamic parameters for an expanded nearest-neighbor model for formation of RNA duplexes with Watson-Crick base pairs. Biochemistry 1998;37:1471935.

48. Jaeger JA, Turner DH, Zuker M. Predicting optimal and suboptimal secondary structure for RNA. Methods Enzymol 1990;183:281-306.

49. Zuker M, Stiegler P. Optimal computer folding of large RNA sequences using thermodynamics and auxiliary information. Nucleic Acids Res 1981;9:133-48.

50. Ongena M, Jacques P. Bacillus lipopeptides: Versatile weapons for plant disease biocontrol. Trends Microbiol 2008;16:115-25. 